\title{
Understanding the Risk of Homelessness for Emerging Adult Foster Care Youth ${ }^{1}$
}

\author{
Francesca Michelini, Randall Cantrell, and Kate Fogarty ${ }^{2}$
}

\section{Introduction}

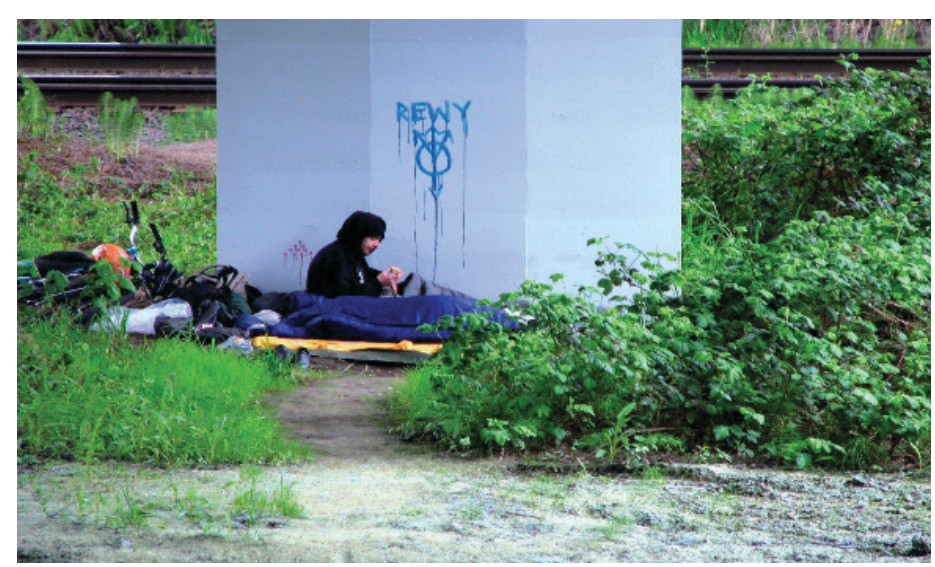

Credit: This photo is licensed under CC BY-SA

Chronic homelessness is defined as a person living in a place not meant for human habitation and having experienced homelessness for at least 12 months or on four separate occasions in the past three years (US HUD, 2021). Homelessness is a global phenomenon. It is estimated that as many as 1.6 billion people worldwide do not have adequate housing. However, this article's focus is on homelessness in the United States, where currently 18 of every 10,000 people are homeless.

Homelessness is not limited to a certain population; it can be experienced by anyone, and it does not discriminate.
According to the National Conference of State Legislatures, one in 10 young adults between the ages of 18 and 25 experiences some form of homelessness. Among those numbers, 33\% have been a part of the foster care system (NCSL, n.d.).

\section{What We Know about Youth in Foster Care in the US}

It is estimated that as of September 2019, 423,997 children were living in foster care in the US. They live in a variety of placement settings. Some children remain in foster care until the age of 18 , although some states allow children to remain in foster care until the age of 21 . Once they have reached the age of 18 , supportive foster care services might be terminated; in some cases, they terminate on their $19^{\text {th }}$, $20^{\text {th }}$, or $21^{\text {st }}$ birthday, depending on the state. The aim of the foster care system is to facilitate reunification of children with their families, but this only occurred at a rate of $47 \%$ (US HHS, 2021).

\section{What happens when youth "age out of foster care"?}

Approximately 25,000 young adults exit the foster care system each year through emancipation. They are typically unprepared to enter society as independent adults (Bender

1. This document is FCS3367, one of a series of the Department of Family, Youth and Community Sciences, UF/IFAS Extension. Original publication date January 2022. Visit the EDIS website at https://edis.ifas.ufl.edu for the currently supported version of this publication.

2. Francesca Michelini, student, Department of Family, Youth and Community Sciences; Randall Cantrell, associate professor, housing and community, Department of Family, Youth and Community Sciences; and Kate Fogarty, assistant professor, Department of Family, Youth and Community Sciences; UF/IFAS Extension, Gainesville, FL 32611.

The Institute of Food and Agricultural Sciences (IFAS) is an Equal Opportunity Institution authorized to provide research, educational information and other services

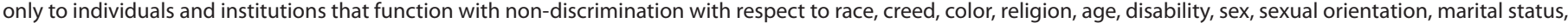

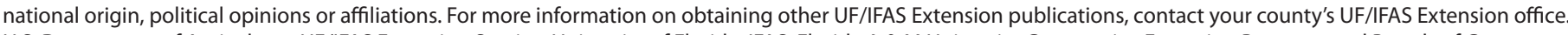
U.S. Department of Agriculture, UF/IFAS Extension Service, University of Florida, IFAS, Florida A \& M University Cooperative Extension Program, and Boards of County Commissioners Cooperating. Andra Johnson, dean for UF/IFAS Extension. 
et al., 2015). According to Bender et al. (2015), barriers these young adults face include:

- Higher rates of unemployment

- Lower rates of high school diploma completion (only 50\% receive a high school diploma before emancipation)

- Increased risk of physical and mental health issues

- Elevated substance abuse and dependency

The foster care system establishes a transitional case plan for these emerging adults usually 90 days before they are set to age out of the system. The transition plan includes providing them with five required document items:

- Birth certificate

- Social Security card

- Health insurance information (if applicable)

- Medical records

- Driver's license or state-issued identification card (www. childwelfare.gov/pubPDFs/extensionfc.pdf)

In addition to these essential legal documents and health information, the youth receive a referral for independent living services to help them prepare for self-sufficiency. These referrals can have complex requirements that may limit their ability to qualify for transitional housing programs. Additional requirements include enrollment in a post-secondary or vocational school, part-time employment, or a documented medical condition that prohibits employment (www.childwelfare.gov/pubPDFs/extensionfc. pdf).

\section{The Reality of Homelessness for Emerging Foster Care Youth}

Many young adults typically rely on familial or community support as they experience the transition from childhood to young adulthood. According to Arnett (2000), the transition from emerging adulthood to young adulthood intensifies through the late twenties and is reached by the age of thirty. Typically, the youth who are emerging from the foster care system lack community and familial support that may be experienced well beyond the age of 18 in a traditional family environment.

The transition plans set up by the foster care programs are designed for a "best scenario" situation, but many times youth in foster care are experiencing emotional trauma and mental health issues that can make a transition even more challenging (Shah et al., 2017). Bender et al. (2015) found that youth in foster care experience several individual risk factors including:

- Low educational attainment

- Reduced financial resources

- Insecure attachments to supportive adults

- Running away from home

- Delinquent behavior

Many of these young adults also experience adverse situations such as mental health disorders, unstable housing, substance abuse, and various forms of trauma (sexual and physical) that can create a barrier to success for the transitional programs set in place by the foster care program (Gross et al., 2017).

Foster care youth are among those with the greatest risk of experiencing homelessness as they emerge from foster care. Research estimates between $11 \%$ and $36 \%$ of youth exiting foster care due to emancipation subsequently experience homelessness (Dworsky et al., 2013). This is a significant number considering that 25,000 youth are estimated to emancipate from foster care each year. One study found that one third of emancipated foster youth aged 19 and older experienced homelessness in California (Fowler et al., 2017).

\section{What can be done to help decrease the risk of homelessness for foster youth?}

When a person ages out of foster care, they are at great risk of losing adequate housing as well as financial, social, and educational support. National foster care policy programs have interventions targeting vital life skill areas to assist foster youth with transitioning from foster care to independent adulthood. These interventions include independent living skills training, much-needed legal documents, and targeted aftercare programs for those who qualify.

Foster care-mandated policies currently start the transitional care plan 90 days before these youth turn 18 to help prepare them for the transition out of the governmentsponsored system. Unfortunately, the current system does not seem to prepare these young adults adequately for success once they are released from the foster care program; according to a national study, only $50 \%$ of foster youth receive the federally mandated available Independent Living Program (ILP) services (Fowler et al., 2017). Therefore, it seems important to explore the option of starting these 
interventions at least one year before the scheduled transition to help prepare for any unanticipated delays.

Exploring the option of early interventions for these youth would allow more opportunities to find stable housing options, which might require more than 90 days to secure. It is important to consider potential improvements that could be implemented to help increase the program's effectiveness.

Volunteering as a youth mentor is a great way to help improve the lives of foster youth during the transition process to independent living. The Children's Network of Southwest Florida offers volunteers the opportunity to serve in various capacities:

- Becoming a foster parent support group mentor

- Organizing supply drives

- Helping with group home projects

- Organizing speaking engagements (neighborhood groups, church, or civic organizations)

- Becoming a volunteer mentor for parents seeking reunification

- (https://www.childnetswfl.org/)

These are just some of the possible ways to make a positive impact on the lives of foster youth. Bringing awareness to the critical needs of emancipated foster care youth is the first step towards making a positive change for the foster youth population.

\section{Conclusion}

Community-based services and programs often struggle to provide homelessness services for those in need. Implementing small changes, such as early intervention services and increased program participation and completion, could be vital to foster youth and reduce this vulnerable population's risk of experiencing homelessness.

\section{Services Available to Foster Care Youth}

https://www.fostercoalition.com/foster-youth-resources (page with links to federal resources)

https://youth.gov/youth-topics/transition-age-youth (youth resource page)

https://www.pathwaysrtc.pdx.edu/pdf/proj2-ThingsNoOneToldMe.pdf (life skills resource page) https://www.aecf.org/blog/resources-for-young-people-infoster-care (Annie Casey Foundation)

https://library.childwelfare.gov/cwig/ws/library/docs/ gateway/Blob/95562.pdf?w=+NATIVE\%28\%27recno\%3D $95562 \% 27 \% 29 \& u p p=0 \& r p p=10 \& r=1 \& m=1$ (foster care to military transition)

\section{References}

Arnett, J. J. (2000). Emerging Adulthood: A Theory of Development from the Late Teens through the Twenties. Retrieved from http://www.jeffreyarnett.com/ARNETT_ Emerging_Adulthood_theory.pdf

Bender, K., Yang, J., Ferguson, K., \& Thompson, S. (2015). Experiences and Needs of Homeless Youth with a History of Foster Care. Children and Youth Services Review, 55(2015), 222-231. http://dx.doi.org/10.1016/j. childyouth.2015.06.007

Children's Network of Southwest Florida. (2017). Children's Network of Southwest Florida. https://www.childnetswfl. org/

Child Welfare Information Gateway. (2017). Extension of Foster Care Beyond Age 18. Retrieved from https://www. childwelfare.gov/pubPDFs/extensionfc.pdf

Child Welfare Information Gateway. (2018). Working with Youth to Develop a Transition Plan. Retrieved from childwelfare.gov/pubPDFs/transitional_plan.pdf

Dworsky, A., Napolitano, L., \& Courtney, M. (2013). Homelessness during the Transition from Foster Care to Adulthood. American Journal of Public Health, 103(Suppl. 2), S318-S323. http://doi.org/10.2105/AJPH.2013.301455

Fowler, P., Marcal, K., Zhang, J., Day, O., \& Landsverk, J. (2017). Homelessness and Aging out of Foster Care: A National Comparison of Child Welfare-Involved Adolescents. Children and Youth Services Review, 77, 27-33. http:// doi.org/10.1016/j.childyouth.2017.03.017

Gross, J., Mann, A., Bluez, G., \& Sulkowski, M. (2017). Helping Homeless, Foster Care, and Juvenile Justice Students. Communique, 45(5), 1+. https://link.gale.com/apps/doc/A492536746/ AONE? $\mathrm{u}=$ gain $40375 \&$ sid=bookmark- $\mathrm{AONE} \& \mathrm{xid}=2 \mathrm{f} 464 \mathrm{fb} 9$

NCSL. (n.d.). Youth Homelessness Overview. Retrieved from https://www.ncsl.org/research/human-services/ homeless-and-runaway-youth.aspx 
Shah, M. F., Liu, Q., Eddy, J. M., Barkan, S., Marshall, D., Mancuso, D., Lucenko, B., \& Huber, A. (2017). Predicting Homelessness among Emerging Adults Aging out of Foster Care. American Journal of Community Psychology, 60, 33-43. doi:10.1002/ajcp.12098

US Department of Health and Human Services (HHS).

(2021). Child Welfare Information Gateway. Retrieved from

https://www.childwelfare.gov/pubs/factsheets/foster/

US Department of Housing and Urban

Development (HUD). (2021). Definition of

Chronic Homelessness. Retrieved from https://

www.hudexchange.info/homelessness-assistance/

coc-esg-virtual-binders/coc-esg-homeless-eligibility/

definition-of-chronic-homelessness/ 